\title{
Introduction to Special Issue on Learning Environments Research Innovations: Policy, Practice, Philosophies
}

\author{
Suzanne Trask ${ }^{1}$ (D) Elaine Khoo ${ }^{2}$ \\ Published online: 15 June 2021 \\ (c) New Zealand Association for Research in Education 2021
}

\section{Background}

There has been increasing interest in learning environments research due to current international and national developments and policy focus on redesigned learning spaces. As a strategic response to this interest, the New Zealand Association for Research in Education's (NZARE) Special Interest Group (SIG) on Learning Environments was established in November 2018. As well as providing a forum for discussion and establishing networks for collaborative research, the SIG aims to support the publication of high-quality learning environments research that informs policy and professional practice in the New Zealand context. An inaugural Learning Environments SIG Symposium was held in October 2019 at the University of Waikato (Learning Environments, n.d.). This was a cross-sectoral event, well attended by representatives from the New Zealand Government and Ministry of Education, academics, professional development providers, teachers, principals, and architects, which led to rich cross-fertilisation of ideas. This special issue is an extension of that forum, inviting contributions from learning environment researchers and practitioners in New Zealand and from overseas. As founding co-convenors of the SIG, we are pleased to present this Special Issue in collaboration with NZARE's flagship journal, the New Zealand Journal of Educational Studies (NZJES).

The area of learning environments research is one that has been active over decades past, with early interest in learning spaces reflected in the open-space school movements beginning in the 1940s and again in the 1980s (Cuban, 2004; Dovey \& Fisher, 2014; Horwitz, 1979; Saltmarsh et al., 2015; Shield et al., 2010; Wright, 2021 , in press). Broadly understood, learning environments can be any external context that supports social and pedagogical opportunities for learning. Learning can occur in multiple spaces where the physical space is but one aspect. The articles in this special issue span dimensions of physical, social, and digital spaces, reflecting

Suzanne Trask

suzanne.trask@auckland.ac.nz

1 Liggins Institute, University of Auckland, Auckland, New Zealand

2 Wilf Malcolm Institute of Educational Research, University of Waikato, Hamilton, New Zealand 
the diversity and scope of learning environments research. They are indicative of the vibrant and emerging contemporary scholarship in this field. Authors in this special issue each make a case for how and in what ways spaces and places in their varied forms and functions matter and can impact profoundly on teaching and learning.

A learning space needs to be resourced in some way. These resources can draw from teachers and students' rich and pre-existing knowledge and experience and the various affordances of furniture, tools and technologies within the learning space. For example, a quiet, enclosed area is designed for connection and collaboration; a whiteboard invites the sharing and communication of information and ideas; sliding walls accommodate different configurations for team teaching and group learning; wired and wireless technologies support digital pedagogies while informal spaces can predispose exploratory, self-paced learning (Dovey \& Fisher, 2014; Ministry of Education, 2016a, b; Trask, 2017; Wright, 2018). Resourced spaces contain structural and systemic affordances and constraints that influence what users perceive they can or cannot do (Bligh, 2018; Imms \& Byers, 2017; Trask, 2021, in press). Thus, the resourced space-user interface is key. In many ways, the basis for undertaking learning environments research is to understand and exploit the combined affordances available in physical, virtual, and social spaces to enhance and facilitate teaching-and-learning.

\section{The Collection of Articles}

The articles in this special issue are authored by New Zealand researchers from disciplines related to education, architecture and design. They incorporate themes relating to philosophy, policy and practice and include contributions to theoretical, context-specific and applied knowledge, connected to broadly-conceived understandings of learning environments. They examine the design and resourcing of physical spaces and digital or virtual/online spaces, social aspects of teacher practice and collaboration, and space-mediated practices pertinent to initial teacher education. In sum, the research studies presented are diverse yet share common aims. Together they speak to the complex, multi-dimensional nature of learning and learning spaces, exploring the relationship between the affordances of the learning environment and user.

Leon Benade, in Theoretical approaches to researching learning spaces, offers a philosophical grounding in the importance of theoretical approaches for analysing innovative building design in education. Benade's review of 136 recent peer reviewed works in the field of learning environments research found a lack of robust theoretical conceptualisation in the field. Benade argues that research and analyses involving theories of spatiality and space in relation to learning environments is fundamental to informing researchers and practitioners and to their adopting a critical stance. This is important for guiding the future generation to generate novel explanations and new/plausible theories for moving the field forward.

Louise Starkey and Bronwyn Wood's article, A critical review of learning environment policy discourse in Aotearoa New Zealand presents a critical analysis of the discourses that underpin New Zealand's ILE (innovative learning environment) built 
environment policy and their resulting responses. Using Bacchi's (1999) 'what's the problem' approach they examine the framing of the 'problems' which the policy documents relating to ILEs purport to address. They illustrate how these problem discourses have been leveraged by policy makers to justify authority and action. Their analyses uncover assumptions and omissions connected to the changing nature of teaching and learning in the twenty-first century. The authors argue that policy documents relating to ILE in New Zealand have relied heavily on a sense of rapid, future-focussed change associated with digital technologies, the global economy, and the future workplace (OECD, 2017). In doing so, Starkey and Wood argue that tensions are created, as reliance on these documents and assumptions tend to overstate the value of things modern while understating the complexities and artistry of teaching and learning as traditionally understood. They conclude that there is a "muddled justification" for the building of "flexible learning spaces" where economic drivers and pedagogical factors are conflated.

In Talking spaces: Architects and educators, Noeline Wright, Trent Thompson and Tim Horne illustrate how representatives from education and architecture sought and found common ground when sharing different perspectives on the design, creation and occupation of learning spaces. Wright et al. present findings from a process of dialogic, autoethnographic discussion in which architects and educators used shared vocabularies to interrogate ideas about space and place in literature and images. The authors argue that architects need to understand how classrooms function for teaching and learning and how teachers and learners interact with spaces as end users. Correspondingly, teachers need to understand what it is that architects need to know as they interpret and blueprint the vision and culture of a school and the unseen teaching/learning processes within. A fundamental idea is that "architects and educators...talk with rather than past each other" (emphasis added). An interesting suggestion is that architects might have a role to play in disrupting the "legacy function" of conventional classrooms, with the inhabiting of new learning spaces enabling a degree of separation from established structures and routines.

Classroom resourcing such as furniture constructs possibilities for how and where learning might happen, with agile furniture inviting different configurations for different learning purposes. Louise Starkey, Victoria Leggett, Craig Anslow and Aniebietabasi Ackley report on research exploring The use of furniture in a primary school student-centred flexible learning environment. The authors' socio-material analysis emphasises the material elements of curriculum, classroom furniture and environment and the social aspects involving the teacher and students. In a redesigned learning space, students had a high degree of flexibility regarding where they worked, and while many factors such as teacher direction and peers influenced their use, individual student preferences were evident. Examples included how they maximised the affordances of different furniture; whiteboard tables were used for collaborative problem solving in mathematics, ottomans and soft furnishings such as bean bags were positioned for comfort. Starkey et al. argue that the students demonstrated environmental competence and autonomy in the way they made use of the available furnishings to support their learning in ways that paid attention to their comfort, collaboration and concentration levels. They make a case for fostering students' environmental competence when teachers work within ILEs. 
Redesigned learning spaces and novel resourcing within learning spaces in the school environment necessitates a rethinking of the way initial teacher education (ITE) programmes prepare pre-service teachers. Addressing the lack of published research in this area, two articles in this issue discuss aspects of ITE regarding ILE environments. Their authors note the complex learning involved for new and preservice teachers when transitioning to ILE and stress the implications of these for ITE.

Jo Fletcher and John Everatt explain that ILE environments typically require teachers and students to work collaboratively, and that this requires pre-service teachers (and all teachers) to develop collegial relationships, excellent communication skills, flexible attitudes and respect for others. The redesign of schooling: What Initial Teacher Education students in New Zealand think about innovative learning environments reports findings from mixed methods research exploring the perceptions of 100 primary ITE pre-service teachers regarding teaching and learning in ILEs. Fletcher and Everatt's analysis of data indicates that their pre-service teacher participants experienced a wide range of professional contexts on practicum. A key finding was that having exposure to and experience in ILE environments during practicum alters perceptions of teaching and learning. Those with more experience of ILEs on practicum were generally more certain about the importance of teacher collaboration and reported more positive perceptions about ILE.

Emily Nelson, Lynn Davies, Leigh Johnson, Kirsty Jones and Nikki O'Connor, in Adapting to the ILE Practicum: New grammar for changing times in Initial Teacher Education, examine the implications of ILEs for initial teacher education (ITE). Nelson et al. explored how ILE practicums were experienced by associate teachers, student teachers and teacher educators. Nelson et al. investigated questions related to ILE and the influence of physical design, the established ITE organisation, educational culture and student dynamics. They note the complexities faced by student teachers in that, "ILEs are configured in particular ways, to shape teaching and learning in line with certain values and expectations". Therefore, according to Nelson et al., practicum in ILE is a different experience and support for pre-service teachers requires different and distinct responses that explicitly address aspects related to the planning and preparation for working in ILEs.

Indicative of increasing interest and research activity in working between formal and semi-formal settings, Victoria Macann and Lucila Carvalho focus on student learning in a public library makerspace. Makerspaces encourage the use of a range of materials and technologies to create products that are of interest. Learning occurs through exploration, questioning, problem-solving and critical thinking using open-ended tasks. Out-of-school makerspaces can promote the development of Science, Technology, Engineering and Mathematics (STEM) identities and skills and facilitate informal and creative learning opportunities and connections between outside school and school learning contexts allowing teachers and learners to share knowledge and skills (Khoo \& Cowie, 2021). Teachers use of public makerspaces to support students' development of digital technology competencies is an example of how technology-enhanced learning in a semi-formal setting such as a public library makerspace can facilitate student formal learning goals (i.e., computational thinking (CT)). McCann and Carvalho's study investigated teacher perceptions on 
the potential of the makerspace to support their students' development of CT skills in line with the introduction of the revised Technology learning area of the New Zealand curriculum (Ministry of Education, 2017). Their study draws from interview findings of primary teachers' impressions, understandings and experiences of workshop attendance with their students at a public library makerspace for teaching and learning of CT skills. Teachers in their study highlighted the value of the makerspace in offering hands-on access to resources and tools that are not usually available in schools.

As illustrated by Macann and Carvalho, learning can take place across semi-formal and formal environments, with one often reinforcing the other. Pursuing this idea of complementarity across both contexts through the affordances of technology-enhanced learning but in the context of higher education, Angela Tsai, Mark Burrell, Sean Sturm and Dawn Garbett offer an alternative for university educators to go beyond awarding coursework marks to encourage student class participation, i.e. the carrot and stick approach. Rethinking the carrot and the stick: A case study of non-grade-bearing learning activities to enhance students' engagement and achievement reports on a study intended to enrich 'out-of-class' learning through the implementation of two optional, non-grade-bearing technology-enhanced informal learning initiatives in a large undergraduate biology course. The first was an out-ofclass digital question, discussion and collaboration space that relied on peer-to-peer tuition (active participation required). The second was a series of optional 'takehome' mock tests with the provision of personalised formative feedback (passive participation). Their longitudinal study findings highlighted the value and complementary nature of the two initiatives in supporting learning. Interestingly, they found that " "passive' participation yielded similar learning benefits to 'active' participation, suggesting that active participation is not an antecedent for learning gains." This has important implications for university educators who require students to engage 'visibly' to gain participation marks.

Finally in this special issue, Claire Coleman and Jane Luton in their article Familiar "innovative" spaces suggest that educators working in learning areas such as the Arts, ECE, Physical Education and Marae-based learning have long been navigating open, flexible spaces that mirror many qualities of innovative learning environments. Three aspects of Remembering, Relating and Rekindling form a framework for analysis that informs a discussion of literature related to these four learning areas. Coleman and Luton interrogate the ways that teachers inhabit and make use of space, suggesting that across the four areas common elements of interpersonal relationships, purposeful alignment of pedagogy and space, and an emphasis on collaboration might offer insight for wider teacher practice.

Together and separately, the articles in this special issue contribute new knowledge in terms of practical, policy and philosophical implications to the field of learning environments. Although there has been some headway made, there is still much ground to cover. For example, what more can we learn from cross-sector dialogue between architecture, building industry, tertiary, and school sectors? How can continued interweaving of formal and informal modes of learning, that exploit digital, physical and social spaces, better promote learning and support all learners? What new theories and models will lead the way in the scholarship of learning and 
exploring the resourced space-user interface? The findings of these studies provide a platform for further research and debate, and we hope will provoke new ideas for forging ahead.

\section{References}

Bacchi, C. (1999). Women, policy and politics: The construction of policy problems. Sage.

Bligh, B. (2018). Does physical space still matter for flexible learning? [Webinar]. Flexible Learning Association of New Zealand. https://hail.to/flexiblelearningNZ/article/arCK5t0

Cuban, L. (2004). The open classroom: Were schools without walls just another fad? Education Next, $4(2), 68$.

Dovey, K., \& Fisher, K. (2014). Designing for adaptation: The school as socio-spatial assemblage. The Journal of Architecture, 19(1), 43-63.

Horwitz, R. (1979). Psychological effects of the "open classroom." Review of Educational Research, 49(1), 71-86.

Imms, W., \& Byers, T. (2017). Impact of classroom design on teacher pedagogy and student engagement and performance in mathematics. Learning Environments Research, 20, 139-152. https://doi.org/10. 1007/s10984-016-9210-0

Khoo, E., \& Cowie, B. (2021). Unlocking Curious Minds Evaluation report: Developing a STEM mobile makerspace and maker educator learning resources. Report submitted to MBIE. Wilf Malcolm Institute of Educational Research (WMIER). https://hdl.handle.net/10289/14176.

Learning Environments. (n.d.). Learning Environments Symposium 2019. https://www.nzare.org.nz/ caucuses-and-sigs/learning-environments/.

Ministry of Education. (2016a). Flexible learning spaces: How the design of spaces can help student achievement. Retrieved from https://www.education.govt.nz/assets/Documents/Primary-Secondary/ Property/Design/Flexible-learning-spaces/FLS-How-the-design-of-spaces-can-help-student-achie vement.pdf.

Ministry of Education. (2016b). Flexible learning spaces: Making spaces work for everyone. Retrieved from https://www.education.govt.nz/assets/Documents/Primary-Secondary/Property/Design/Flexi ble-learning-spaces/FLS-Making-spaces-work-for-everyone.pdf.

New Zealand Ministry of Education. (2017). Digital Technology curriculum-Hangarau Matihiko. https://technology.tki.org.nz/Technology-in-the-NZC.

OECD. (2017). The OECD handbook for innovative learning environments. OECD Publishing.

Saltmarsh, S., Chapman, A., Campbell, M., \& Drew, C. (2015). Putting "structure within the space": Spatially un/responsive pedagogic practices in open-plan learning environments. Educational Review, 67(3), 315-327. https://doi.org/10.1080/00131911.2014.924482

Shield, B., Greenland, E., \& Dockrell, J. (2010). Noise in open plan classrooms in primary schools: A review. Noise \& Health, 12(49), 225-234. https://doi.org/10.4103/1463-1741.70501

Trask, S. (2017). Reconstructing senior science learning in flexible learning spaces. In W. Imms, \& M. Mahat (Eds.), Transitions Australasia 2017: What is needed to help teachers utilize space as one of their pedagogic tools? (pp. 79-87). Retrieved from https://www.iletc.com.au/publications/proce edings

Trask, S. (2021). A portrait of teaching and learning in innovative learning environments. In N. Wright, \& E. Khoo (Eds.), Pedagogy and partnerships in innovative learning environments: Case studies from New Zealand contexts. Springer.

Wright, N. (2018). Becoming an innovative learning environment: The making of a New Zealand secondary school. Springer.

Wright, N. (2021). An historical perspective of learning spaces. In N. Wright, \& E. Khoo (Eds.), Pedagogy and partnerships in innovative learning environments: Case studies from New Zealand contexts. Springer.

Publisher's Note Springer Nature remains neutral with regard to jurisdictional claims in published maps and institutional affiliations. 